\section{Contactless hospitality in a post-Covid-19 world}

\author{
Sima Rahimizhian and Foad Irani \\ Faculty of Tourism, Eastern Mediterranean University, Famagusta, North Cyprus
}

Contactless hospitality in post-Covid-19 world

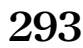

\begin{abstract}
Purpose - This study aims to investigate the mediating effect of consumer innovativeness in the relationship between tourism inclinations and revisit intention. This study focuses on the significance of innovative technologies that help to reduce physical contact and optimize operations and services to offer a direct added value to hospitality businesses and their customers.

Design/methodology/approach - This study uses a self-reported survey design using an online questionnaire to collect data from randomly selected potential tourists. The survey was in English. Data collection was carried out from June to July 2020 , and a valid sample of 272 responses was obtained for data analysis.

Findings - The data were analyzed using ADANCO software. The study suggested that tourism inclination has both direct and indirect impacts on revisit intention through innovativeness.

Originality/value - This study allows a deeper understanding of the importance of contactless and low laborer-interaction technologies that help hospitality industry to win back pandemic-sensitive customers once this outbreak is over. To do this, the mediating effect of consumer innovativeness on their intention to revisit a tourist destination post-Covid-19 was investigated.
\end{abstract}

Keywords Covid-19, Touch-less technology, Tourism inclinations, Innovativeness, Revisit intention, Hospitality

Paper type Research paper

\section{Introduction}

The Covid-19 epidemic began in Wuhan, China, in December 2019, and is spreading rapidly throughout the world (Lipistch et al. 2020). It was declared as a pandemic in March 2020 by the World Health Organization, with countries such as China, Italy, Spain and the USA being hit the hardest. At present (August 24, 2020), there have been 23,311,719 confirmed cases, including 806,410 deaths (www.who.int). The uncertainty and further restrictions imposed due to the outbreak of Covid-19 had a dramatic impact on travel and tourist destinations. Covid-19 has indeed expedited the immersion of new technologies and applications within tourism and hospitality operations. Technology novelties that might have been mainly designed for launching as innovations or extra services are suddenly becoming obligations in a time where some people are cautious of traveling (Ivanov et al., 2020). Despite the devastating blow, Covid-19 gives the tourism industry a chance to recover itself. All industries worldwide are attempting to sustain consumer trust and keep the economy going. Rules such as mask-wearing, hand-sanitizing and social distancing are being admitted as new norms, and touch-free or contactless technologies are being considered as solutions to keep people isolated while continuing to conduct businesses. These solutions could be replacing actual menus with scannable QR codes, contactless hotel check-in capabilities, mobile room keys, touchless payments and in-app ordering (Fipra, 2020). Practically most aspects of the hospitality activity can now be accessed by

(C) Sima Rahimizhian and Foad Irani. Published in International Hospitality Review. Published by Emerald Publishing Limited. This article is published under the Creative Commons Attribution (CC BY 4.0) licence. Anyone may reproduce, distribute, translate and create derivative works of this article (for both commercial and non-commercial purposes), subject to full attribution to the original publication and authors. The full terms of this licence may be seen at http://creativecommons.org/licences/by/4.0/legalcode

Received 26 August 2020 Revised 13 November 2020 18 November 2020 Accepted 19 November 2020 
IHR

35,2

customers' own mobile devices, provided that hotels have embraced the appropriate software.

The Covid-19 outbreak will certainly increase continuous changes, and, predictably, the tourism industry pays more attention to avoid tourism activity in mass tourism destination (Fipra, 2020). How people spend their leisure time is shifting due to the outbreak and related social distancing rules, and these attitudes are likely to be sustained. Consumers are adopting technology more than ever to maintain all aspects and results of isolation. For businesses operating in the travel industry, it is necessary to keep up with the latest travel technology inclinations. While the provision of services and experiences in the hospitality and tourism industry has steadily been influenced by technological advances, research on tourist inclination to adjust and adapt to innovations in technology-driven services is incomplete (Wang, 2015). Recognition and employing technology trends can enhance the efficiency of business operations and further improve the consumer experience; hotels and other businesses must keep up-to-date with the emerging travel technology trends, so they do not fall behind competitors. More research is currently required to define and target highly inclined customers to embrace new goods or services as an innovative approach to their requirements (Rahimizhian et al., 2020b). In the tourism domain, this notion has not been researched (Hwang and Hyun, 2016; Sandvik et al., 2014).

A touchless, adaptable and customizable automation platform featuring all front-office operations and answering particular business requirements could be a solution that the industry needs post-Covid-19. To welcome visitors again, post-Covid-19, hospitality businesses and tourist destinations should have a solution that can help them deal with uncertainty. Thus, automated and contactless services can come into action. Acknowledging the absence of either theoretical or experimental studies on the customer and contactless services connection, researchers took a cognitive route to a sufficient understanding of such a relationship (Ramadan et al., 2017). The main aspects of the context of this paper contribute to the theory of planned behavior (TPB), which was applied to propose a conceptual structure for this research. As one of the most popular models of attitude-behavior associations (Fishbein and Ajzen, 1977), TPB offers a conceptual framework for assessing attitudes toward the use of contactless service and its expectation and intent of use. The essence of this causal model is the belief that the direct determinant of a particular behavior is the innovation of consumers in the usage of contactless services.

This study aimed to examine the influence of tourism inclination on travelers' revisiting intention through innovativeness by adopting a structural equation model (SEM). Therefore, the study attempts to answer the questions regarding the impact that touchless technologies might have on tourist's desire to visit tourism destinations post-Covid-19. Thus, the objective of this research study is designed to answer how technological innovations might act as an appropriate solution for those tourist destinations that are economically dependent on tourism revenue. The proposed research model has been developed and tested (see Figure 1). Discussions of findings, theoretical and practical implications, as well as suggestions for future research are addressed.

\section{Theoretical framework and hypothesis development \\ 2.1 Tourism inclination and innovativeness}

The Covid-19 spread forced tourism practitioners to seek out technological innovations for sustainable tourism development (Ivanov et al., 2020). Generally, tourists seem quite receptive to technological advancements (Zhong et al., 2020). The tourists' attitude perceived technologies positively since the risk level reduces and reliability increases (Kaushik et al., 2015). Innovativeness and diffusion of innovations are well-established constructs of 
consumer research (Goldsmith and Flynn, 1992). Innovativeness was defined by Rogers (1995) as "the degree to which a person or other unit of adoption is relatively earlier in adopting new ideas than other system members" (p. 22). Each consumer is distinguished from another by this particular variable difference. Innovation is seen as motivated by the noveltyseeking, the demand for stimulation, the independence from the knowledge of others, and the need for uniqueness (Roehrich, 2004). In line with previous studies in the tourism context, tourists are different in their acceptance of new technologies and the attitudes toward them (Webster and Ivanov, 2019). In other words, consumers who exhibit greater innovativeness over a new service may have a greater possibility of being an early adopter of innovative offerings than other customers (Hadi et al., 2020; Strutton et al., 2011).

According to Koschate-Fischer et al. (2018), experiencing a life event leads to an increase in consumer innovativeness. A study by Wen et al. (2005) noted that the SARS outbreak had impacted tourists' inclinations and preferences, particularly the types of tours and travel patterns. While people tend to be more involved in outdoor and eco-tourism events, and city residents prefer to travel to the suburbs and countryside, the need for social distancing has raised many new issues. Many post-pandemic tourists will demand touchless innovative options. Such innovative solutions enable them to enter their information in advance of arrival at the airport or hotels on their smartphone and privilege access to all essential touchpoints based on a touchless facial match. Therefore, the following hypothesis is suggested:

H1. Tourism inclination positively influences innovativeness.

\subsection{Innovativeness and revisit intention}

Innovativeness is to predict the level of personal innovativeness before the adoption process happens (Kirton, 1976). As the majority of consumers tend to continue innovation post-Covid-19, involving innovative consumers is essential to the success of unique services. Bhatti (1970) examined innovativeness in the context of mobile commerce adoption. Agarwal and Prasad (1998) stated that innovativeness affects consumers' attitudes in terms of technology advantages. Moreover, innovativeness has been considered as a factor influencing online travel shopping in previous investigations (Lee et al., 2007; Steinbauer and Werthner, 2007). It has also been incorporated in prior Technology Acceptance Model (TAM) studies in tourism, although not to a great extent.

The tourism and hospitality industry is sensitive to health diseases, and as it is happening, the Covid-19 caused many degradations to the industry; therefore, paradoxical actions of enhancing the current quality and adopting novel strategies always are required to the sustainable development of this industry. Consumer innovativeness is the desire to do new things (Midgley and Dowling, 1978). On four subjects, Roehrich (2004) discusses the forces that cause this predisposition. They are the need for stimulation, seeking novelty, freedom

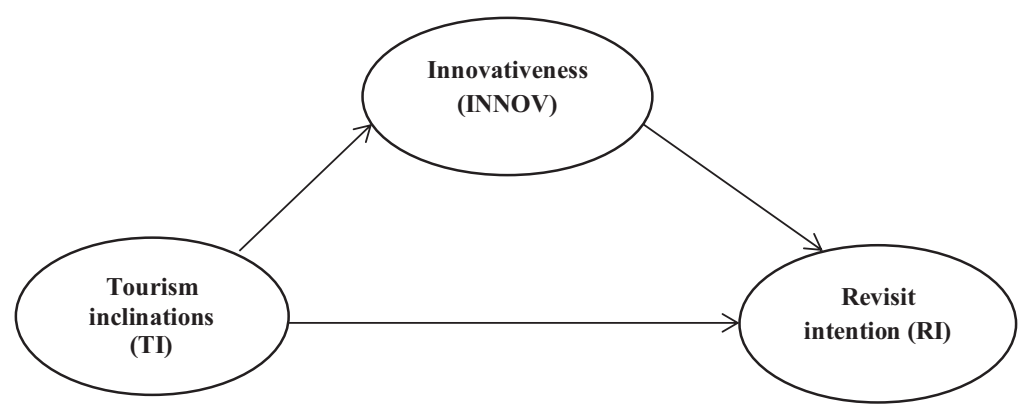

Figure 1.

Proposed research model 
IHR

35,2

296

from the communicated experience of others and the need for uniqueness. The person is motivated by these forces to (1) look for new information, (2) drive them to differentiate themselves by owning rare items and (3) independence of judgment in innovative decisions (Hirschman, 1980; Roehrich, 2004). These studies conclude that consumers' innovativeness makes them inclined to try new services as well as their visit frequency to the place. A study by Boyle and Ruppel (2006) ascertained that individual innovativeness has a significant positive association with online purchasing intention. Also, Lu (2003) observed compatible results through research that found statistically significant support for the positive and direct impact of innovativeness on consumers' continuance intention.

Touchless facilities reduce the risks and encourage the visitors to experience the new era of tourism and hospitality industry. Therefore, these kinds of protocols that reduce the risk of diseases will help both the industry to promote touristic activities and the organizations to retain their visitors (Hwang and Hyun, 2013). Therefore, innovativeness positively influences the tourism and hospitality industry. Thus, it is hypothesized that:

H2. Innovativeness positively influences revisit intention.

\subsection{Tourism inclination and revisit intention}

The uncertainty and further restrictions that arose due to the outbreak of Covid-19 has had a dramatic impact on travel and tourist destinations. Measures of social distancing have significant effects on participation in activities. Most people are temporarily jobless or work remotely from home, and most leisure events have been canceled. Travel demand is therefore rising, and many nations have now seen dramatic decreases in traffic flow - reducing congestion and air pollution - as well as in public transport traveling (Goldbaum, 2020). This situation is temporary, and, once this crisis is over, participation in the out-of-home activity and travel demand is expected to increase. However, if social distancing rules are eased, tourists might still fear social contact, affecting involvement in the activity and travel. Therefore, tourism recovery typically begins locally.

Tourists prefer short-distance traveling, and their priority normally goes to easier way of experiencing travel; however, providing comfort zone can encourage the tourists to go beyond traveling domestic. People intrinsically are curious to experience, and the conditions can motivate them to go beyond. According to a report by Kiesnoski (2020), there are more future reservations for the holidays now, compared to the same period last year, which indicates that many people who are unable to travel at present are planning for later in the year. Accordingly, the following hypothesis is formed:

H3. Tourism inclination negatively influences revisit intention.

\subsection{Mediating effect of innovativeness}

Uncertainty is strongly related to the degree of innovativeness. By rising the degree of innovativeness, more technological discontinuities and market-related changes occur (Salomo et al., 2007). However, innovativeness was principally supposed to remain constant in an individual's life; the particularistic aspect proved that innovativeness is socially influenced (Hirschman, 1980). Thus, it would seem that any rebound in travel and tourism, brought to a screeching end by the Covid-19 pandemic, will start again, and the travel plans will increase for the following month (Kiesnoski, 2020).

Consumer innovativeness as a preference to explore and try novel ideas infers a desire to experience new services before other customers do (Roehrich, 2004). Decline in tourism and economic crisis could generally enhance innovativeness and create competitive advantages for hospitality companies and communities that can transform the concept into distinct forms of operation and management. According to Wood (2010), people who are currently working 
in new, changing and unpredictable environments would be more frequently open to fresh and unfamiliar choices. Consistent with this perception, Koschate-Fischer et al. (2018) affirmed that consumer innovativeness was positively affected by particular events (e.g. tourism inclinations). Therefore, as innovation increases, consumers' intention toward revisiting a touristic destination is expected to increase during Covid-19; thus, it is hypothesized that:

H4. Innovativeness mediates the relationship between tourism inclinations and revisits intention.

\section{Method}

\subsection{Procedure and sample}

In the beginning, the idea of this research was conceptualized based on the extant literature, and the research team clarified the aim of this research. The questionnaire was developed by using items from the relevant literature. The questionnaires were designed and posted by SurveyMonkey online as a self-administrated online questionnaire through social media. Hair et al. (2010) suggested that to ensure the validity, 10-15 participants per measurement items should be recruited. There are 11 measurement items in this study; thus, the aim was to collect a minimum of 165 responds. The pilot study was conducted by posting the online survey through SurveyMonkey. The collected answers were 57, which were reduced to 42 after discarding the incomplete copies. The pre-test sample was extracted from the final data set after obtaining the instrument reliability. The participants participated as a volunteer, and their confidentiality was assured by the research team (Kwol et al., 2020).

\subsection{Measures}

The questionnaire was distributed among the participants about their intention to revisit destinations during the pandemic by using innovation in tourism activities. The variables are measured by a 5 -point Likert scale ranging from 1 - strongly disagree to 5 - strongly agree. The measurement items were adapted from extant literature to ensure reliability and validity:

(1) The tourism inclination was measured through 5 items adapted from Wen et al. (2005).

(2) To operationalize the innovativeness, 3 items were adapted from Agarwal and Prasad (1998).

(3) Revisit intention were measured by three items adapted from Meng and Chio (2016).

\section{Results}

\subsection{Demographics of participants}

A total of 300 data were collected using SurveyMonkey. However, only 279 responses were returned, of which 272 were useable. The demographics show that $168(61.8 \%)$ were female, and $104(38.2 \%)$ of the participants were male. The majority of the participants, that is 154 $(56.6 \%)$, were tourists who had traveled at least once a year in the recent passing year and 118 $(43.4 \%)$ were those participants who had not been traveling during the last year.

\subsection{Validity and reliability of the data}

For this study, using ADANCO, the confirmatory factor analysis (CFA) was used to evaluate the validity and reliability of the measurement model. The measures of composite reliability 
IHR

35,2

\section{8}

and Cronbach's alpha should be greater than 0.7 to be reliable (Hair et al., 2010; Nunnally and Bernstein, 1994). For ADANCO, reliabilities of the constructs were measured using the Dijkstra Henseler's rho_A coefficient, which is supposed to be greater than 0.70 (Dijkstra and Henseler, 2015). In this regard, the study measures are reliable. The ADANCO was used to check the convergent validity to check the outer loading and average variance extracted (AVE). The required threshold for outer loading and AVEs should be greater than 0.5, as suggested by Hair et al. (2010). Findings represent that all variables are valid and reliable, as illustrated in Table 1.

Additionally, the convergent validity of this study was confirmed. The discriminant validity of the constructs is confirmed as shown in Tables 2 and 3, by applying the heterotrait-monotrait (HTMT) method as well as Fornell-Larcker criterion (Ali et al., 2018; Henseler et al., 2015; Fornell and Larcker, 1981).

\subsection{Structural model result}

In this study, ADANCO conducted testing the hypotheses and obtaining the beta coefficients for direct paths and determination coefficients $(R 2)$, as shown in Table 4. Bootstrap analysis was conducted using the sample size of 5,000 at a confidence interval of $97.5 \%$ to acquire the $t$-values and their associated $p$-values. As noted in INNOV and RI Table $4,(R 2)$ was 0.356 and 0.373 , respectively. Table 4 represented that the effect size $\left(f^{2}\right)$ of TI on RI was small $(0.105)$ and strong on INNOV (0.554). INNOV on IR had a small effect.

\subsection{Direct and indirect effects}

H1 suggests a direct impact of TI on INNOV. Findings indicate that TI influences INNOV significantly $(\beta=0.597, p<0.000)$, thus providing sufficient evidence for supporting H1. The second hypothesis shows that INNOV has a significant impact on the RI of tourists. Result also reveals that INNOV has a significant effect on $\mathrm{RI}(\beta=0.363, p<0.000)$; thus, hypothesis 2 has also been supported. The positive association of innovativeness and revisit intention was expected since innovation in tourism activities positively affects the visitors to adopt technologies for intention to revisit by influencing their attitudes of traveling safely (Diallo and Collin-Lachaud, 2019). Hypothesis 3 proposes that TI negatively influences RI. The results confirmed that TI significantly influences RI $(\beta=0.319, p<0.000)$; thus, H3 is supported. Additionally, it was expected that due to the spread of Covid-19 globally,

\begin{tabular}{|c|c|c|c|c|c|}
\hline & $\mathrm{OL}$ & Cronbach's alpha & $\mathrm{CR}$ & rho_A & AVE \\
\hline Tourism inclination & & 0.88 & 0.91 & 0.88 & 0.67 \\
\hline TI1 & 0.827 & & & & \\
\hline TI2 & 0.778 & & & & \\
\hline TI3 & 0.862 & & & & \\
\hline TI4 & 0.817 & & & & \\
\hline TI5 & 0.813 & & & & \\
\hline Smart tourism innovativeness & & 0.86 & 0.91 & 0.86 & 0.78 \\
\hline INNOV1 & 0.867 & & & & \\
\hline INNOV2 & 0.906 & & & & \\
\hline INNOV3 & 0.875 & & & & \\
\hline Revisit intention & & 0.90 & 0.94 & 0.91 & 0.83 \\
\hline RI1 & 0.901 & & & & \\
\hline RI2 & 0.927 & & & & \\
\hline RI3 & 0.911 & & & & \\
\hline
\end{tabular}

outer loading

Note(s): OL implies outer loadings; CR implies composite reliability; AVE implies average variance extracted 
inclination of the tourism industry influences the visitors' attitude toward revisiting destination with touristic attractions. Finally, this study proposed hypothesis 4 that INNOV mediates the relationship between TI and RI. The mediation hypothesis of our study was tested based on the two-step approach (Nitzl et al., 2016). The findings recorded in Table 5 demonstrated that indirect TI [INNOV] RI paths (estimate $M 1=0.2172, t=4,5,747$ ) are statistically significant because there is no zero in the respective $97.5 \%$ CIs. Therefore, there was support for hypothesis 4 .

\section{Discussion and limitations}

This study aimed to assess the innovativeness as a mediator between the relationships of tourism inclination and revisit intention. The results pointed out a negative association between tourism inclination and revisit intention. In other words, the degradation of tourism

\begin{tabular}{lccc}
\hline Construct & TI & RI & INNOV \\
\hline TI & & & \\
IR & 0.5954 & & \\
INNOV & 0.6812 & 0.6209 &
\end{tabular}

Contactless hospitality in post-Covid-19 world

299 
IHR

35,2

\section{0}

activities due to the spread of Covid-19 globally, resulted in less revisit intention among visitors. However, it can be inferred that if innovative technologies would prepare visitors regarding visiting tourist destination in a way that would make experience of traveling safe, their willingness to revisit may be increased. Consequently, the perception of innovativeness in terms of touchless technologies in tourism positively influences the visitors' behavioral intention (i.e. revisit intention) (Tran et al., 2020).

This study focused on consumers' viewpoints of the future of contactless services and considered their readiness to receive the service by employing the consumer innovativeness theory. The innovativeness in tourism usually plays a significant role in enhancing revisit intention (Hadood and Irani, 2020; Hasan et al., 2019). The significant and positive effect of innovativeness on revisit intention indicates that more innovative people are more likely to take action to travel to the destination once the pandemic is over. These data are compatible with Pagani et al.'s (2011) findings, proposing that managers should recognize their most innovative customers to participate and contribute to activities among users of new services. These results pave the way for future research into the relationship between tourism-specific innovation and consumer behavior during and after Covid-19. Consumers with a higher level of innovativeness will be more likely to contribute to new products and services (e.g. touchless services) that can also create a way of establishing a mutually profitable connection.

The effects of innovativeness on revisit intention received much attention in the literature; however, the effects of tourism inclination on revisit intention have been slightly investigated (Meng and Cui, 2020). Because of Covid-19 outbreak, tourists encountered great fear and threats to their health and uncertainties about their life. This posed a big problematic issue for destinations to retain their tourists. It is difficult to retain visitors by destinations that are affected by Covid-19 during the lockdown. However, by adopting innovative technological strategies and implementing them, tourist destinations can maintain and retain the tourists under the circumstances of Covid-19 outbreak.

Because of its impact, the Covid-19 public health issue is projected to have unprecedented influences on global tourism. Visitors' behaviors and expectations and their effect on the global tourism market need to be thoroughly studied so that business practitioners and policymakers can develop a more sustainable field (Rahimizhian et al., 2020a). Demographic developments in tourism will also contribute to the creation of new opportunities, which can be explored by researchers and practitioners together. The Covid-19 outbreak has already had an immense effect on every society and industry. Tourism scholars and practitioners should take careful note of this tragedy, so that they can educate industry activities. Such global health issues represent strong reasons for understanding the industry holistically in terms of its effect on the climate, economy and travelers themselves. While travelers are reconsidering how they travel, following this pandemic, practitioners too will think of ways to make meaningful improvements to the tourism industry by adopting technological innovation toward tourism activities.

This study has various managerial contributions. The travel and tourism industry reflects a background in which innovation in products and services is highly pertinent. This research provides a better understanding and targeting of the most innovative consumers for the management of tourism businesses. Managers should enhance the design and development of contact with fewer services that might have an immense impact on pandemic-sensitive customers' choice. By focusing on innovations and the prerequisite of customer choice designs, managers will be more proficient at developing their operational planning and decision-making. The study's findings can be applied to develop a decision-support guide that can help in achieving the "what-if" type of outlines. Before making a notable investment in terms of money and effort, managers can investigate the possible values and willingness to pay for each proposed service innovation. 
This study has important consequences in empirical and practical terms, and also like any other studies, it is not without limitations. This study mainly focused on the tourists, and the lack of a diverse population is one of the limitations. Therefore, the results can only be applied to the tourism sector. Future research should also include other significant sectors of the tourism industry, such as different faculties, sectors, private agencies and hotels. A single traveler variety was included in the study, but future research could look at the different variety of travelers. Additionally, a bigger data set can be applied for more analysis to realize if innovation in technologies toward experiencing tourism activities truly makes an impact. In the current study, the interaction of tourism inclination and revisit intention was borderline insignificant; therefore, in future studies, other elements should be considered, such as personal traits and tourists' attitude, with a larger sample data, which may lead to different results.

\section{Conclusion}

It is expected that tourism development will have adverse long-term impacts due to Covid19. These adverse impacts are perceived differently by tourists since they are from different cultural backgrounds. With the vital impacts of the Covid-19 pandemic, this study offers crucial insight to assist tourism administrators and decision-makers in designing unique, successful approaches to improving the tourism sector, especially enhancing the travel events. This study aimed to examine if innovativeness in experiencing tourism activities has an impact on tourists during the pandemic. The findings of the study point out that innovativeness has a significant effect on enhancing revisit intentions of the tourists to travel to tourist destinations due to the inclination of tourism activities due to Covid-19 disaster.

\section{References}

Agarwal, R. and Prasad, J. (1998), "A conceptual and operational definition of personal innovativeness in the domain of information technology", Information Systems Research, Vol. 9 No. 2, pp. 204-215.

Ali, F., Rasoolimanesh, S.M., Sarstedt, M., Ringle, C.M. and Ryu, K. (2018), "An assessment of the use of partial least squares structural equation modeling (PLS-SEM) in hospitality research", International Journal of Contemporary Hospitality Management, Vol. 30 No. 1, pp. 514-538.

Bhatti, T. (1970), "Exploring factors influencing the adoption of mobile commerce", The Journal of Internet Banking and Commerce, Vol. 12 No. 3, pp. 1-13.

Boyle, R.J. and Ruppel, C.P. (2006), "The effects of personal innovativeness, perceived risk, and computer self-efficacy on online purchasing intent", Journal of International Technology and Information Management, Vol. 15 No. 2, p. 5.

Diallo, M.F. and Collin-Lachaud, I. (2019), "Impact of hedonic evaluation of technological innovations on revisit intention in a store digitalization context", International Journal of Technology and Human Interaction (IJTHI), Vol. 15 No. 4, pp. 38-53.

Dijkstra, T.K. and Henseler, J. (2015), “Consistent partial least squares path modeling”, MIS Quarterly, Vol. 39 No. 2.

Fipra (2020), Despite Devastating Blow, Covid19 Gives Tourism Industry A Chance to Redeem Itself, [online] available at: https:/fipra.com/update/despite-devastating-blow-covid19-gives-tourismindustry-a-chance-to-redeem-itself/ (accessed 24 August 2020).

Fishbein, M. and Ajzen, I. (1977), Belief, Attitude, Intention, and Behavior: An Introduction to Theory and Research, Addison-Wesley, Reading, MA.

Fornell, C. and Larcker, D.F. (1981), "Evaluating structural equation models with unobservable variables and measurement error", Journal of Marketing Research, Vol. 18 No. 1, pp. 39-50. 
IHR

35,2

Goldbaum, C. (2020), Subway Service Is Cut by A Quarter Because of Coronavirus, [online] Nytimes.com. available at: https:/www.nytimes.com/2020/03/24/nyregion/coronavirus-nyc-mtacuts-.html?searchResultPosition $=6>$ (accessed 25 August 2020).

Goldsmith, R. and Flynn, L.R. (1992), "Identifying innovators in consumer product markets", European Journal of Marketing, Vol. 26 No. 12, pp. 42-55.

Hadi, D.M., Irani, F. and Gökmenoğlu, K.K. (2020), "External determinants of the stock price performance of tourism, travel, and leisure firms: evidence from the United States", International Journal of Hospitality and Tourism Administration, pp. 1-17, doi: 10.1080/ 15256480.2020 .1842838 .

Hadood, A.A.A. and Irani, F. (2020), "Impact of economic sentiment and economic policy uncertainty on travel and leisure stock return", Journal of Hospitality and Tourism Insights, Vol. ahead-ofprint No. ahead-of-print, doi: 10.1108/JHTI-05-2020-0070.

Hair, J., Black, W. and Babin, B. and Anderson R. (2010), Multivariate Data Analysis, 7th ed., Prentice Hall, Upper Saddle River, NJ.

Hasan, M.K., Abdullah, S.K., Lew, T.Y. and Islam, M.F. (2019), "The antecedents of tourist attitudes to revisit and revisit intentions for coastal tourism", International Journal of Culture, Tourism and Hospitality Research, Vol. 13 No. 2, pp. 218-234.

Henseler, J., Ringle, C.M. and Sarstedt, M. (2015), "A new criterion for assessing discriminant validity in variance-based structural equation modeling", Journal of the Academy of Marketing Science, Vol. 43 No. 1, pp. 115-135.

Hirschman, E.C. (1980), "Innovativeness, novelty seeking, and consumer creativity", Journal of Consumer Research, Vol. 7 No. 3, pp. 283-295.

Hwang, J. and Hyun, S.S. (2013), "The impact of nostalgia triggers on emotional responses and revisit intentions in luxury restaurants: the moderating role of hiatus", International Journal of Hospitality Management, Vol. 33, pp. 250-262.

Hwang, J. and Hyun, S.S. (2016), "Perceived firm innovativeness in cruise travelers' experience and perceived luxury value: the moderating effect of advertising effectiveness", Asia Pacific Journal of Tourism Research, Vol. 21 No. sup1, pp. S101-S128.

Ivanov, S., Webster, C., Stoilova, E. and Slobodskoy, D. (2020), "Biosecurity, crisis management, automation technologies, and economic performance of travel, tourism and hospitality companies -a conceptual framework", Tourism and Hospitality Companies, in press, doi: 10. 1177/1354816620946541.

Kaushik, A.K., Agrawal, A.K. and Rahman, Z. (2015), "Tourist behaviour towards self-service hotel technology adoption: trust and subjective norm as key antecedents", Tourism Management Perspectives, Vol. 16, pp. 278-289.

Kiesnoski, K. (2020), "Travel changed after 9/11; here's how it will look after the Covid-19 pandemic finally recedes", [online] CNBC. available at: https:/www.cnbc.com/2020/05/10/heres-howtravel-will-change-after-the-covid-19-pandemic-recedes.html (accessed 25 August 2020).

Kirton, M. (1976), "Adaptors and innovators: a description and measure", Journal of Applied Psychology, Vol. 61 No. 5, p. 622.

Koschate-Fischer, N., Hoyer, W.D., Stokburger-Sauer, N.E. and Engling, J. (2018), "Do life events always lead to change in purchase? The mediating role of change in consumer innovativeness, the variety seeking tendency, and price consciousness", Journal of the Academy of Marketing Science, Vol. 46 No. 3, pp. 516-536.

Kwol, V.S., Eluwole, K.K., Avci, T. and Lasisi, T.T. (2020), “Another look into the knowledge attitude practice (KAP) model for food control: an investigation of the mediating role of food handlers' attitudes", Food Control, Vol. 110, p. 107025.

Lee, H.Y., Qu, H. and Kim, Y.S. (2007), "A study of the impact of personal innovativeness on online travel shopping behavior-a case study of Korean travelers", Tourism Management, Vol. 28 No. 3, pp. 886-897. 
Lipsitch, M., Swerdlow, D.L. and Finelli, L. (2020), "Defining the epidemiology of Covid-19-studies needed", New England Journal of Medicine, Vol. 382 No. 13, pp. 1194-1196.

Lu, J., Yu, C.S., Liu, C. and Yao, J.E. (2003), “Technology acceptance model for wireless Internet”, Internet Research.

Meng, B. and Choi, K. (2016), "Extending the theory of planned behaviour: testing the effects of authentic perception and environmental concerns on the slow-tourist decision-making process", Current Issues in Tourism, Vol. 19 No. 6, pp. 528-544.

Meng, B. and Cui, M. (2020), "The role of co-creation experience in forming tourists' revisit intention to home-based accommodation: extending the theory of planned behavior", Tourism Management Perspectives, Vol. 33, p. 100581.

Midgley, D.F. and Dowling, G.R. (1978), "Innovativeness: the concept and its measurement", Journal of Consumer Research, Vol. 4 No. 4, pp. 229-242.

Nitzl, C., Roldan, J.L. and Cepeda, G. (2016), "Mediation analysis in partial least squares path modeling", Industrial Management and Data Systems.

Nunnally, J.C. and Bernstein, I.H. (1994), Psychological Theory, McGraw-Hill, New York, NY.

Pagani, M., Hofacker, C.F. and Goldsmith, R.E. (2011), "The influence of personality on active and passive use of social networking sites", Psychology and Marketing, Vol. 28 No. 5, pp. 441-456.

Rahimizhian, S., Avci, T. and Eluwole, K.K. (2020a), "A conceptual model development of the impact of higher education service quality in guaranteeing edu-tourists' satisfaction and behavioral intentions", Journal of Public Affairs, Vol. 20 No. 3, e2085.

Rahimizhian, S., Ozturen, A. and Ilkan, M. (2020b), "Emerging realm of 360-degree technology to promote tourism destination", Technology in Society, Vol. 63, p. 101411.

Ramadan, Z.B., Farah, M.F. and Mrad, M. (2017), “An adapted TPB approach to consumers' acceptance of service-delivery drones”, Technology Analysis and Strategic Management, Vol. 29 No. 7, pp. 817-828.

Roehrich, G. (2004), “Consumer innovativeness: Concepts and measurements”, Journal of Business Research, Vol. 57 No. 6, pp. 671-677.

Rogers, E.M. (1995), Diffusion of Innovations, 4th ed, The Free Press, New York.

Salomo, S., Weise, J. and Gemünden, H.G. (2007), "NPD planning activities and innovation performance: the mediating role of process management and the moderating effect of product innovativeness", Journal of Product Innovation Management, Vol. 24 No. 4, pp. 285-302.

Sandvik, I.L., Duhan, D.F. and Sandvik, K. (2014), "Innovativeness and profitability: an empirical investigation in the Norwegian hotel industry", Cornell Hospitality Quarterly, Vol. 55 No. 2, pp. 165-185.

Steinbauer, A. and Werthner, H. (2007), "Consumer behaviour in e-tourism", Information and Communication Technologies in Tourism 2007, Springer, Vienna, pp. 65-76.

Strutton, D., Taylor, D.G. and Thompson, K. (2011), "Investigating generational differences in e-WOM behaviours: for advertising purposes, does $\mathrm{X}=\mathrm{Y}$ ?", International Journal of Advertising, Vol. 30 No. 4, pp. 559-586.

Tran, Q.X., Dang, M.V. and Tournois, N. (2020), "The role of servicescape and social interaction toward customer service experience in coffee stores. The case of Vietnam", International Journal of Culture, Tourism and Hospitality Research, Vol. 14 No. 4, pp. 619-637.

Wang, E.S.T. (2015), "The role of player innovativeness in adopting new online games: bidimensional and hierarchical perspectives", International Journal of Technology Marketing, Vol. 10 No. 3, pp. 236-247.

Webster, C. and Ivanov, S.H. (2019), "What do people think robots should do in hospitality and tourism? Preliminary findings from a global study of market segments", Proceedings of the AIRSI2019 Conference "Artificial Intelligence and Robotics in Service Interactions: Trends, Benefits, and Challenges, pp. 55-71.
Contactless hospitality in post-Covid-19 world 
IHR

35,2

304
Wen, Z., Huimin, G. and Kavanaugh, R.R. (2005), "The impacts of SARS on the consumer behaviour of Chinese domestic tourists", Current Issues in Tourism, Vol. 8 No. 1, pp. 22-38.

Wood, D.J. (2010), "Measuring corporate social performance: a review", International Journal of Management Reviews, Vol. 12 No. 1, pp. 50-84.

Zhong, L., Sun, S., Law, R. and Zhang, X. (2020), 'Impact of robot hotel service on consumers' purchase intention: a control experiment", Asia Pacific Journal of Tourism Research, Vol. 25 No. 7, pp. 780-798, doi: 10.1080/10941665.2020.1726421.

\section{Corresponding author}

Sima Rahimizhian can be contacted at: sima.rahimi@emu.edu.tr

For instructions on how to order reprints of this article, please visit our website: www.emeraldgrouppublishing.com/licensing/reprints.htm Or contact us for further details: permissions@emeraldinsight.com 